\title{
North Korean nuclear test of October 9th, 2006: The utilization of health Canada's radionuclide monitoring network and environment Canada's atmospheric transport and dispersion modelling
}

\author{
T.J. Stocki ${ }^{1}$, R.K. Ungar ${ }^{1}$, R. D'Amours ${ }^{2}$, M. Bean ${ }^{1}$, K. Bock ${ }^{1}$, I. Hoffman ${ }^{1}$, \\ E. Korpach ${ }^{1}$ and A. Malo ${ }^{2}$ \\ ${ }^{1}$ Radiation Protection Bureau, Health Canada, 2720 Riverside Dr., AL6604C, Ottawa, ON, \\ Canada, K1A 1C1 \\ ${ }^{2}$ Canadian Meteorological Centre, Environment Canada, 2121 Trans-Canada Highway, \\ Dorval, QC, Canada H9P 1J3
}

\begin{abstract}
Since January 1959, Health Canada has monitored environmental levels of radioactive fallout, to ensure the health and well being of Canadians. This work has evolved to include explosion verification for the Comprehensive nuclear-Test-Ban Treaty by monitoring the concentration of radioxenon in the atmosphere. Detection of Xe at Yellowknife by the monitoring system of Health Canada combined with the atmospheric transport and dispersion models (ATDM) of Environment Canada and seismic timing data have shown that the source of this Xe was most likely from the North Korean nuclear test of October $9^{\text {th }}$, 2006. Historical and real time monitoring data on the distribution of Xe releases from Chalk River Labs, the major source of anthropogenic background to Yellowknife were studied. Careful review of other large Xe-133 measurements at Yellowknife with ATDM was used to understand the October 2006 measurements of Xe. This allowed us to conclude that the Xe-133 detected at Yellowknife could be attributed to a release from the October nuclear test in North Korea. Health Canada and Environment Canada have demonstrated that Xe detection combined with ATDM is a viable technology for treaty verification.
\end{abstract}

\section{INTRODUCTION}

Radiation Protection Bureau (RPB) within Health Canada performs environmental and occupational radiation protection. RPB's responsibilities include nuclear verification, incident monitoring, and an active role as a member of the Comprehensive nuclear-Test-Ban Treaty (CTBT). To facilitate these roles, Health Canada maintains radiation detector networks across Canada, one of which consists of $\mathrm{NaI}(\mathrm{Tl})$ detectors [1] that measure the pulse height of gamma rays from radioactive noble gases and then converts these spectra into measured values for air KERMA rate. The operation and calibration of these detectors have been described by Grasty [2, 3]. Beside the $\mathrm{NaI}(\mathrm{Tl})$ detector in Ottawa is a radioxenon analyzer system known as the Système de Prélèvement d'air Automatique en Ligne avec l'Analyse des radioXénons (SPALAX) [4, 5]. The SPALAX measures the activity concentration of four

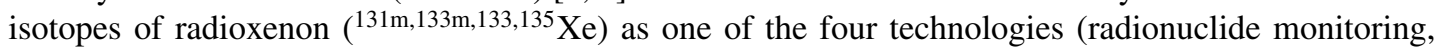
seismic, hydroacoustic, and infrasound) for compliance verification of the CTBT [6]. In order to assist with compliance verification of the CTBT, the radioxenon background has been thoroughly studied in Ottawa [4], and in terms of atmospheric transport down the Otttawa Valley [1]. This paper discusses the radioxenon background in the Ottawa region in terms of its distribution as a source of radioxenon background in Yellowknife, Canada. This turned out to be a key piece of information in regards to determining the source of radioxenon observed in Yellowknife in October of 2006 [7]. This paper describes the radioxenon distributions measured in two different ways: 1) the $\mathrm{NaI}(\mathrm{Tl})$ network, and 2) by through yearly safety reports by Chalk River Laboratories. All of this together was done in order to 
determine whether or not Chalk River was the source of Radioxenon measured at Yellowknife after the announced nuclear test by North Korea [7].

\section{MEASUREMENTS}

\subsection{SPALAX}

The SPALAX is a device that automatically and continuously samples radioxenon. The SPALAX separates the radioxenon from the air by the use of membranes and activated charcoal ovens. Then the SPALAX extracts and concentrates radioxenon by a factor of $3 \times 10^{6}$. After separating the radioxenon, it uses a high purity germanium detector to measure the X-rays and gamma-rays from the radioxenon to determine the activity concentration in air. The SPALAX takes daily samples and is better described elsewhere [5].

\subsection{The NaI(Tl) Network (Fixed Point Network)}

The NaI(Tl) network consists of 3" by 3" cylindrical thallium activated sodium iodide detectors which are pointed skyward to measure radioactivity. These detectors are set up to report air KERMA for health physics concerns, but after careful study, we can convert these values to activity concentration [8, 9]. This careful study was a result of understanding the radioxenon transport down the Ottawa Valley [1]. These detectors are more fully described in that study and in the two papers by Grasty [2, 3].

\subsection{Literature search of Chalk River Lab releases}

The third method used to understand the radioxenon background in Ottawa was through a literature search of safety reviews of Chalk River Laboratories, where weekly total noble gas emissions are reported [10-14]. This was done to help with the understanding of background radioxenon emissions and how they relate to the nuclear event that occurred on October $9^{\text {th }}, 2006$ in North Korea.

This involved extracting points from several years of weekly emission graphs from Chalk River to understand the largest magnitude of emission that could ever have been emitted in one day from the facility. This work solidified the notion that the magnitude of the Chalk River emissions could not account for the detection in Yellowknife.

\section{RESULTS}

\subsection{SPALAX previous to Oct 2006 radioxenon detections in Yellowknife}

Under normal conditions, the SPALAX in Yellowknife measures very small traces of radioxenon in Yellowknife. Prior to October 2006, a few relatively larger amounts of radioxenon were measured by using the SPALAX. Several days in March 2005, the SPALAX measured radioxenon in Yellowknife, see Figure 1. The calculated values are based on an assumed $10^{14} \mathrm{~Bq}$ release from Chalk River, Ontario. The atmospheric transport modelling was done by using a three dimensional Lagrangian Particle Dispersion Model, MLDP0 [15, 16], which was set up to do random displacement in the vertical direction and used first order horizontal diffusion. MLDP0 also used the numerical weather data assimilation and prediction (NWP) system of Environment Canada. The model accounted for radioactive decay of the radionuclides being transported. MLDP0 was run in both forward and inverse modes. It included the effects of wet and dry deposition.

It is clear that these results are consistent with a release from Chalk River. The results are considered in good agreement considering that this is transport of radionuclides over a distance of more than $2900 \mathrm{~km}$. Thus it is possible to determine the source of radionuclides using atmospheric transport modelling. It is also possible to locate a source of radioxenon using long range atmospheric modelling. 


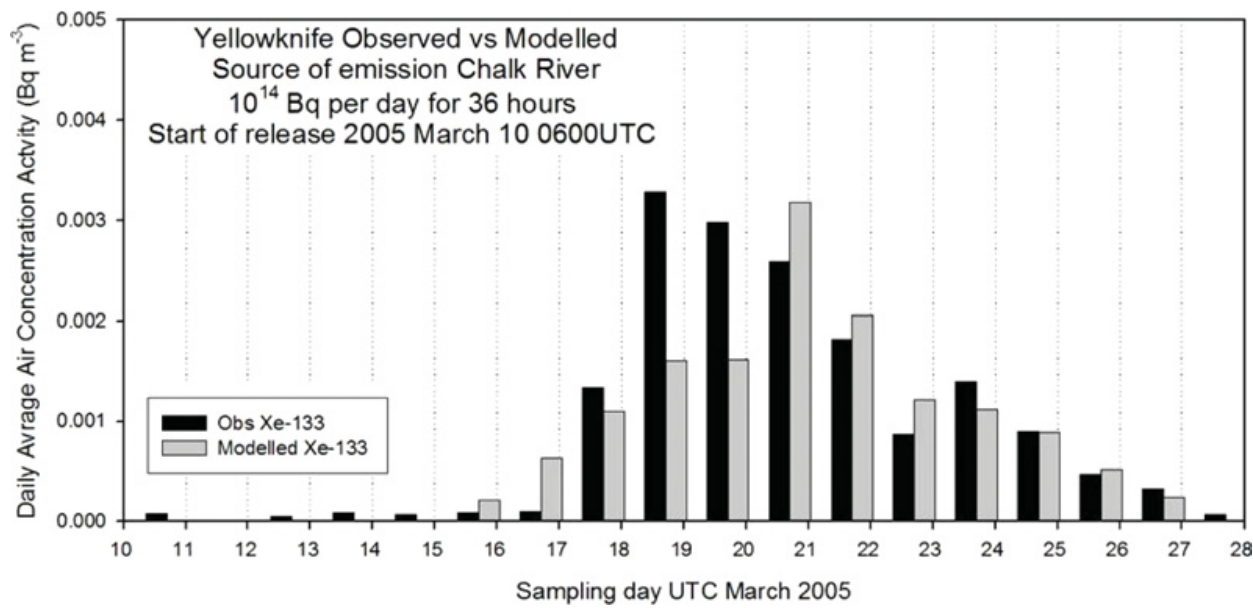

Figure 1. Measurements and modelling of radioxenon in Yellowknife from the March 2005 increase in radioxenon.

\subsection{Xenon background distributions}

\subsubsection{Xenon measured from $\mathrm{NaI}(\mathrm{Tl})$ detectors}

Data from these detectors were graphed in the form of distributions of Xe-133 for six locations: Chapeau, Chalk River, Sheenboro, the Town of Chalk River, Deep River, and Petawawa on a log probability plot. Then certain days of interest from October $1-15^{\text {th }}, 2006$ were also plotted to see where they occured. Figure 2 show an example of this for Sheenboro. Note that these certain days of interest day are nowhere near the largest amount measured. This is showing that the releases from Chalk River were not very large during the time after the test.

\subsubsection{Xenon measured from the stack releases}

Data from Chalk River safety reports were gathered by reading values off the graphs and putting the values in a spreadsheet. The graphs were reproduced as a quality control and then the results of these graphs were formed in the percent rank graphs as in Figure 3. Information on the releases during the period in Oct, where also plotted on this graph. These weekly total xenon stack releases in period up to October $21^{\text {st }}, 2006$, had a range of 5 to $44 \mathrm{TBq}$ and a median value of $13.6 \mathrm{TBq}$ [17]. These were near the annual median value of about $30 \mathrm{TeV} . \mathrm{MeV}$ [10-14]. Similar to the section 3.2.1 results, these October releases are nowhere near as large as the largest releases from Chalk River. This shows that the amount of radioxenon from Chalk River was fairly small after the announced test.

\subsection{Atmospheric Transport Modelling for the Oct 2006 measurements}

Figure 4 shows the measurements from the SPALAX in Yellowknife, about two weeks after the announced test. On this graph are also calculations from atmospheric transport modelling, with three different assumptions. The three assumptions were: a continues release from Chalk River Laboratories; sudden venting from Kilchu, North Korea; slow venting from Kilchu, North Korea with a maximum 2 days after the announcement. The timing and location for the last two assumptions was set by seismic information.

In Figure 4, it is clear that the measurements are not consistence with radioxenon from Chalk River, but rather, it is consistent with radioxenon which had come from Kilchu. These results show that there is a very good possibility that the source was the announced test by North Korea. 


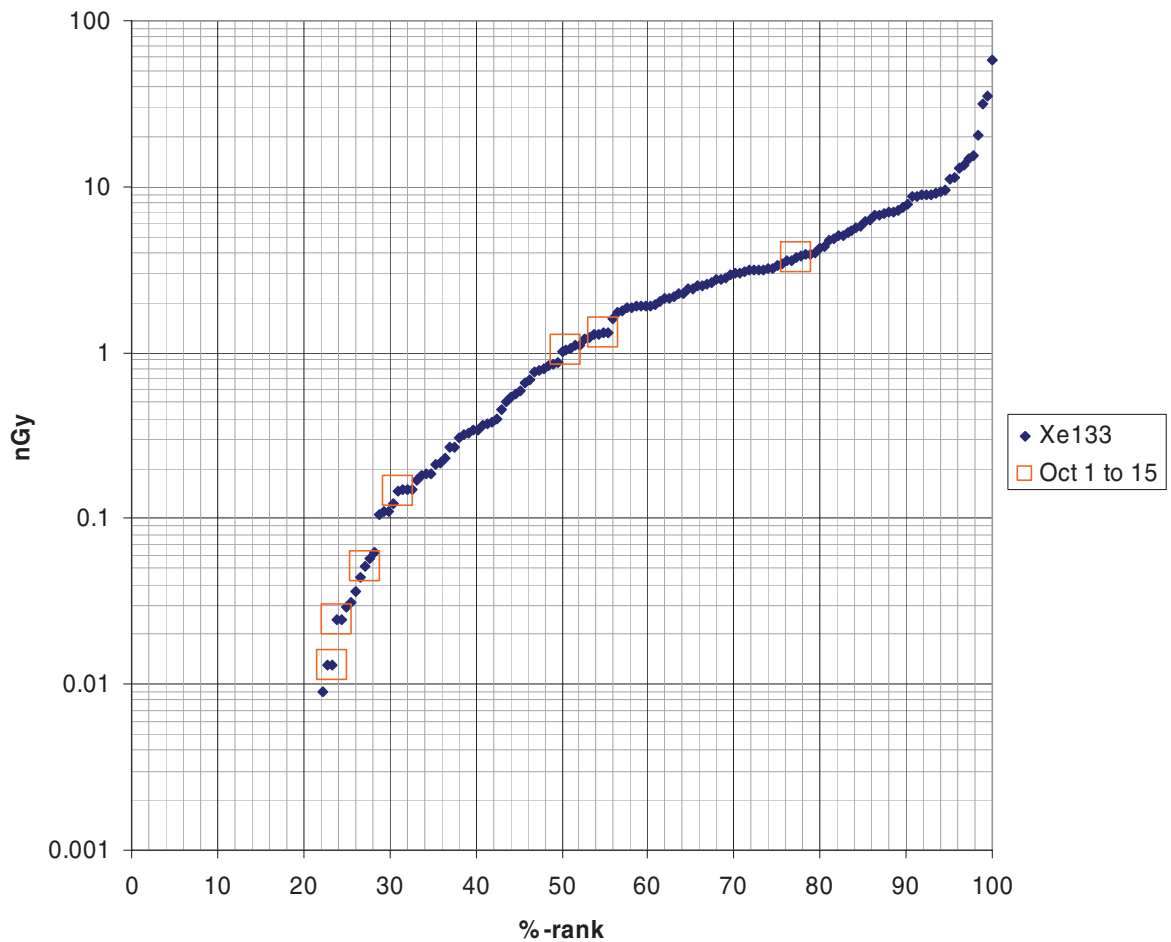

Figure 2. The Xe-133 measurements in $\mathrm{nGy}$ as a function of \%-rank for $\mathrm{NaI}(\mathrm{Tl})$ detector in Sheenboro. The $\mathrm{x}$-axis shows the order of the measurements from lowest to highest.

CRL Medical Isotope Production Weekly Noble Gas Stack Emissions 2001-2005

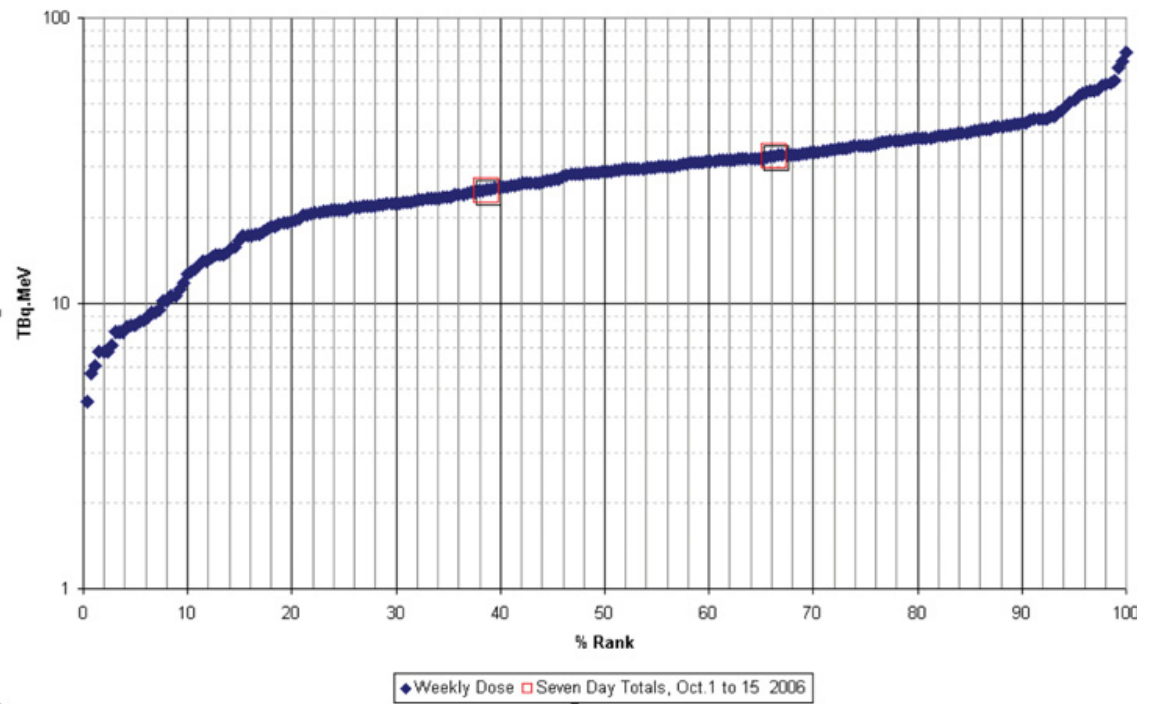

Figure 3. Weekly stack emissions from Chalk River, 2001-2005. The x-axis shows the order of the measurements from lowest to highest. 


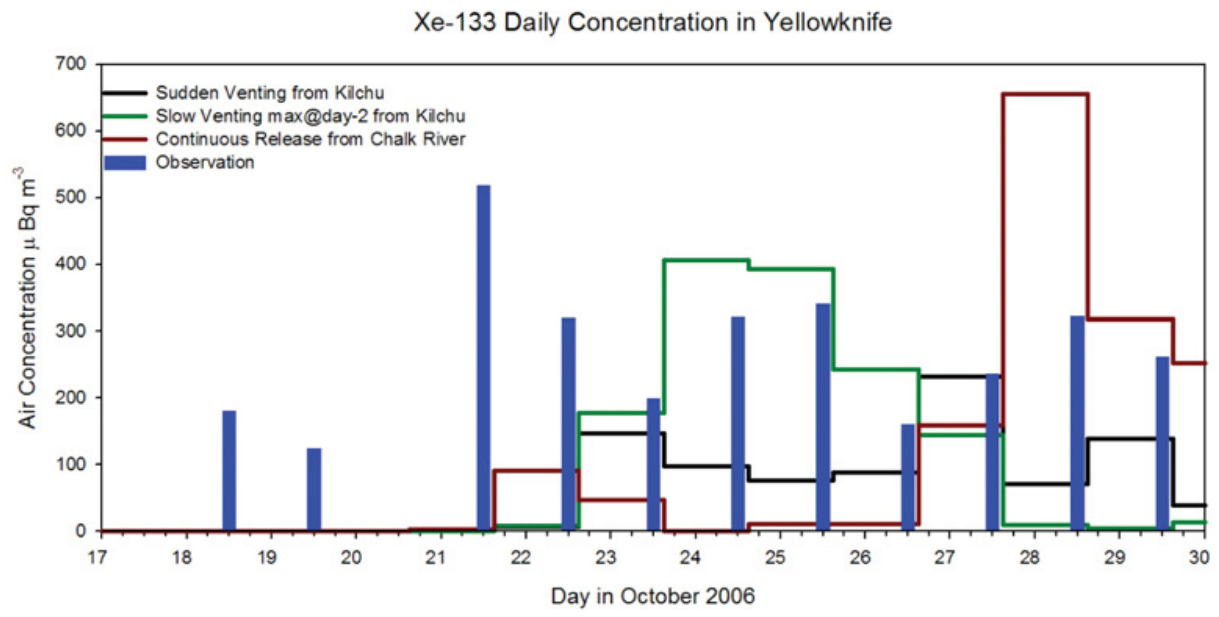

Figure 4. Modelling and measurements of radioxenon in Yellowknife. The blue bars are measurements made at the Yellowknife station. The others are the results of atmospheric transport modelling of radioxenon from various sources (Kilchu and Chalk River).

\section{CONCLUSION}

In conclusion, after a thorough investigation of the radioxenon in the Ottawa area, which contributes to the background signal in Yellowknife, and after atmospheric transport modelling, one finds that the most likely source of radioxenon measured in Yellowknife was from the announced test by North Korea.

\section{References}

[1] Stocki T.J., Armad P., Heinrich Ph., Ungar R.K., D’Amours R., Korpach E.P., Bellivier A., Taffary T., Malo A., Bean M., Hoffman I., Jean M., Measurement and Modeling of Radioxenon Plumes in the Ottawa Valley J. Environ. Radioact. 99 (2008) 1775-1788.

[2] Grasty R.T., Walters B.R.B., Hovgaard J., and LaMarre J.R. Radiat. Protect. Dosim. 94, (2001) 309-316.

[3] Grasty R.T., Hovgaard J., and LaMarre J. Radiat. Protect. Dosim. 95, (2001) 249-256.

[4] Stocki, T.J., Blanchard X., D’Amours R., Ungar R.K., Fontaine, J.P., Sohier, M., Bean M., Taffary T., Racine J. Tracy B.L., Brachet G., Jean M., and Meyerhoff D., J. Environ. Radioact. 80, (2005) 305-326.

[5] Fontaine J.P., Pointurier F., Blanchard X., and Taffary T. J. J. Environ. Radioact. 72, (2004)129_ 135.

[6] Sullivan J. D.. Phys. Today 51, March (1998) 24-29.

[7] Saey P.R.J, Bean M., Becker A., Coyne J., D’Amours, R., DeGeer, L.-E., Hogue R., Stocki, T.J., Ungar, R.K., and Wotawa G. Geophys. Res. Lett. 34 (2007) L20802.

[8] Stocki, T.J, Lo M.-C. Lo, Bock K., Beaton L.A, Tisi S.D.R., Tran A., Sullivan T., Ungar R.K. Radioprotection 44 (2009) 735-739.

[9] Stocki T.J., Beaton L.A., Tran A., Bock K., and Ungar R.K. Nucl. Instr. Meth. A580, (2007) 683-686.

[10] Deaconescu, R. AECL Annual Safety Review Molybdenum-99 Production Facility Annual Safety Review 2001. AECL-MISC-303-01 Rev. 0. Chalk River, Ontario (2002).

[11] Thompson, L.W. Annual Safety Review Molybdenum-99 Production Facility Annual Safety Review 2002. AECL-MISC-303-02 Rev. 1. Chalk River, Ontario (2003). 
[12] Thompson, L.W. Annual Safety Review Molybdenum-99 Production Facility Annual Safety Review 2003. AECL-MISC-303-03 Chalk River, Ontario (2004).

[13] Thompson, L.W. Annual Safety Review Molybdenum-99 Production Facility Annual Safety Review 2004. AECL-MISC-303-04 Rev 0. Chalk River, Ontario (2005).

[14] Thompson, L.W., Annual Safety Review Molybdenum-99 Production Facility Annual Safety Review 2005. AECL-MISC-303-05 Rev 0. Chalk River, Ontario (2006).

[15] D’Amours, R. and Malo A., "A Zeroth Order Lagrangian Particle Dispersion Model MLDP0", Internal publication, Canadian Meteorological Centre, Environmental Emergency Response Section (2004) 19 pp.

[16] D’Amours R., Malo, A., Servranckx R., Bensimon, D., Trudel, S., Gauthier J.-P., J. Geophysl Res, 115 (2010), D00L11, 1-11.

[17] Legree B. private communication. 